\section{Diffuse idiopathic skeletal hyperostosis: an unusual cause of difficult intubation}

Edward T. Crosby BSc MD FRCPC, ${ }^{*}$

S. Grahovac MD FRCPC $\dagger$
A case is reported in which anterior osteophytes on the cervical vertebra, in combination with a subglottic stenosis, resulted in distortion of the airway and led to unexpected difficulties during intubation. The osteophytes, associated with the syndrome of diffuse idiopathic skeletal hyperostosis (DISH) were centred at the midcervical level and resulted in anterior displacement of the larynx with an acute angulation of the trachea just below the larynx. This acute angulation, immediately above an unrecognized subglottic stenosis, rendered it impossible to pass all but the smallest endotracheal tube. Diffuse idiopathic skeletal hyperostosis is an ossifying diathesis leading to bone formation in spinal and extraspinal sites, paravertebral osteophyte formation and ligamentous calcification and ossification. Ossification of the anterior longitudinal ligament is common, may be discontinuous, and is often more marked in the thoracolumbar spine than elsewhere. However, isolated and predominant cervical spinal involvement may occur. Diffuse idiopathic skeletal hyperostosis occurs primarily in the elderly population and is often associated with the syndromes of osteoarthritis and assification of the posterior longitudinal ligament (OPLL). Difficult intubation resulting from anatomical abnormalities of the cervical spine is rare. Although radiological evaluation may be useful in assessing the airway in patients deemed to be at risk for difficult intubation, it cannot be recommended for screening patient populations on a routine basis because of the cost and anticipated extremely low yield. Careful clinical evaluation of the airway before operation and having an approach to the unexpected difficult intubation are emphasized.

\section{Key words}

ANATOMY: cervical spine;

INTUBATION, TRACHEAL: complications, technique;

SURGERY: orthopaedic;

SYNDROMES: diffuse idiopathic skeletal hyperostosis.

From the Departments of Anaesthesia* and Radiology, $\dagger$ University of Ottawa, Ottawa General Hospital, Module A-11, 501 Smyth Road, Ottawa, Ontario, K1H 8L6.

Address correspondence to: Dr. Crosby.

Accepted for publication 28th August, 1992.
Cette observation décrit une difformité des voies respiratoires causée par la présence d'ostéophytes situés en avant des vertèbres cervicales. Accompagnée d'un oedème sous-glottique, elle fut la cause de difficultés inattendues lors de l'intubation. Les ostéophytes, centraux et médiocervicaux associés au syndrome dhyperostose squelettique diffuse idiopathique provoquèrent un déplacement antérieur du larynx à angle aigu avec la trachée, juste sous le larynx. Cette formation d'un angle, localisé en haut d'un oedème sous-glottique méconnu, a rendu impossible le passage diune canule endotrachéale du plus petit calibre. L'hyperotose squelettique idiopathique diffuse constitue une diathèse ossifiante entrainant la formation de sites asseux spinaux et extraspinaux, d'ostéophytes paravertébraux, à la calcification et à l'ossification ligamentaires. L'ossification du ligament longitudinal antérieur est fréquente, peut être interrompue et est souvent plus importante au rachis thoracolombaire. Cependant, une atteinte isolée à prédominance cervico-rachidienne peut survenir. L'hyperostose idiopathique squelettique diffuse survient dans la population âgée et s'associe souvent aux syndromes ostéo-arthritiques et à l'ossification du ligament longitudinal postérieur. Les difficultés d'intubation résultant d'anomalies anatomiques de la colonne cervicale sont rares. Bien que l'evaluation radiologique puisse être utile dans l'évaluation des voies respiratoires du patient comportant un risque d'intubation difficile, elle ne peut être recommandée pour le dépistage de populations de façon régulière à cause du coût et du rendement anticipé extrèmement faible. La nécessité d'une évaluation préopératoire méticuleuse des voies aériennes et une approche systématique de l'intubation difficile imprévue s'imposent.

There are a number of algorithms available to guide in the evaluation of the airway for the purposes of predicting the degree of difficulty expected during tracheal intubation. ${ }^{1,2}$ These algorithms emphasize evaluation of the anatomy of the structures of the face, jaw and oropharynx and direct little, if any, attention towards evaluation of the anatomy or kinematics of the cervical spine. However, disordered anatomy of the cervical spine, both congenital and acquired, may influence the ease of intubation. We report a patient in whom anterior osteophytes on the cervical spine, associated with the syndrome of diffuse idio- 
pathic skeletal hyperostosis (DISH), resulted in displacement and angulation of the airway and led to unexpected difficulties during tracheal intubation.

\section{Case report}

The patient was a 71-yr-old male who was experiencing increasing gait ataxia and spasticity suggestive of chronic cervical cord compression. A myelogram was carried out and considerable cord compression was evident, most notably at the $\mathrm{C}_{3}$ spinal level and related to posterior osteophyte formation. He was scheduled for elective decompression and anterior fusion at that spinal level. He had a history of coronary artery disease and he had suffered a myocardial infarction in the remote past. His exercise tolerance was considerably impaired by his neurological symptoms but he reported no angina. His only medication was oral nitrates. Examination of his upper airway revealed that the soft palate, fauces, uvula and pillars were easily visualized and he was assigned to Mallampati Class I. ${ }^{\prime}$ Flexion and extension of the cervical spine appeared to be reasonably well preserved and a difficult intubation was not anticipated. He received premedication with sublingual lorazepam.

On arrival in the operating room an $i v$ infusion was started in a forearm vein and noninvasive monitors (fivelead ECG with continuous ST-segment analysis, automated BP cuff, pulse oximeter, neuromuscular stimulator) were secured. Preinduction medication (sufentanil 35 $\mu \mathrm{g}$ and d-tubocurarine $3 \mathrm{mg}$ ) was administered $i v$ and his lungs were denitrogenated with oxygen. General anaesthesia was induced with thiopentone $225 \mathrm{mg}$, and succinylcholine $140 \mathrm{mg}$ was given for muscle relaxation. Following loss of muscle twitch, intubation was attempted with the help of a lighted stylet, the neck being maintained in the neutral position. Although good tracheal illumination could be easily obtained, the endotracheal tube could not be passed in two attempts. The stylet was abandoned and with the neck maintained neutral, direct laryngoscopy was performed. Laryngoscopy was Mallampati Grade I with the laryngeal inlet clearly and completely visualized. ${ }^{1}$ However, an unexpected finding was the appearance of what appeared to be the inner aspects of the anterior tracheal wall occupying about $80 \%$ of the aperture immediately below the vocal cords. An attempt was made to pass a styleted $8.0 \mathrm{~mm}$ and then a $7.5 \mathrm{~mm}$ endotracheal tube but the tubes impacted against the subglottic obstruction. A $7.5 \mathrm{~mm}$ flexible, armoured tube over a stylet was passed in the same manner and with the same result. The flexible tube was then passed with the stylet directed posteriorly to no avail.

${ }^{*}$ C-Line Tubestat ${ }^{\odot}$ Xomed-Treace, Inc, 6743 Southpoint Dr North, Jacksonville, Florida, 32216.
With the neurosurgeon standing by, the neck was gently flexed in an attempt to reduce the obstruction, again without success. The difficult intubation tray was brought into the room and a second anaesthetist was called to assist in the assessment and management of the patient's airway. A flexible tube changer was then passed easily into the trachea, well below the apparent trouble spot. However, it again proved impossible to pass either a standard or flexible armoured endotracheal tube over the tube changer and it was withdrawn. Finally a $5.0 \mathrm{~mm}$ endotracheal tube, approximately the same calibre as the tube changer, was passed, directed through the posterior aspects of the laryngeal inlet and then passed easily beyond the obstruction. The tube was secured and the surgery commenced shortly thereafter.

During the first direct attempt at intubation the upper airway was topicalized with lidocaine spray $(80 \mathrm{mg})$. General anaesthesia was maintained during the intubation attempts with isoflurane (1.5\% end-tidal concentration) in oxygen and mask-bag ventilation was maintained by hand without difficulty. One additional intravenous increment of succinylcholine $(60 \mathrm{mg})$ was given in order to maintain muscle relaxation. Succinylcholine was not felt to be contraindicated in this patient because of the relative sparing of both upper motor neurons and muscle bulk by his myelopathic process. ${ }^{3}$ Blood pressure, heart rate, including continuous ST-segment analysis, and pulse oximetry were monitored during the intubation attempts and all variables remained at or near baseline values.

The surgery lasted about four hours and blood loss was estimated at $300 \mathrm{ml}$. Fluid therapy consisted of crystalloid $(2000 \mathrm{ml})$ intraoperatively. At the end of surgery the trachea was extubated and the patient was taken to the recovery room in good condition. His neurological status was unchanged from the preoperative state. About five days after surgery radiographic, tomographic and computerized tomographic studies of his cervical spine and trachea were carried out for assessment of his airway (Figures 1-3). The radiologist reported the presence of anterior osteophyte formation of 8 and $14 \mathrm{~mm}$ on the vertebral bodies of $\mathrm{C}_{5}$ and $\mathrm{C}_{6}$, respectively, with anterior displacement of the larynx and trachea. In addition, in the subglottic region of the trachea, there was evidence of narrowing that was consistent with subglottic tracheal stenosis.

The patient was interviewed to determine possible aetiological factors relating to the tracheal stenosis. $\mathrm{He}$ reported that, as a young child, he had been severely ill with diphtheria. The clinical history and radiographic studies were reviewed with a senior consultant otolaryngologist who was of the opinion that the findings were consistent with post-diphtheritic cicatricial laryngotracheal stenosis. 


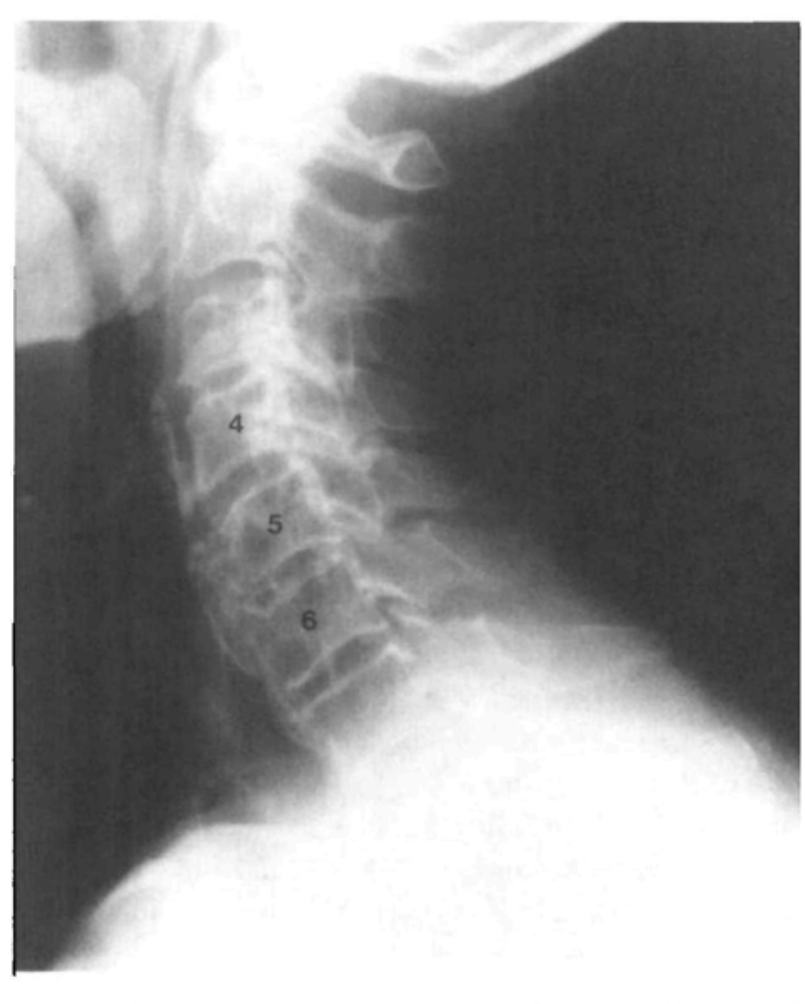

FIGURE 1 Lateral radiograph of the cervical spine. There is ossification in the soft tissues anterior to $\mathrm{C}_{4}$, a large bridging osteophyte from $C_{5-6}$, a smaller osteophyte connecting $C_{6-7}$ and ossification in the posterior longitudinal ligament at multiple levels.

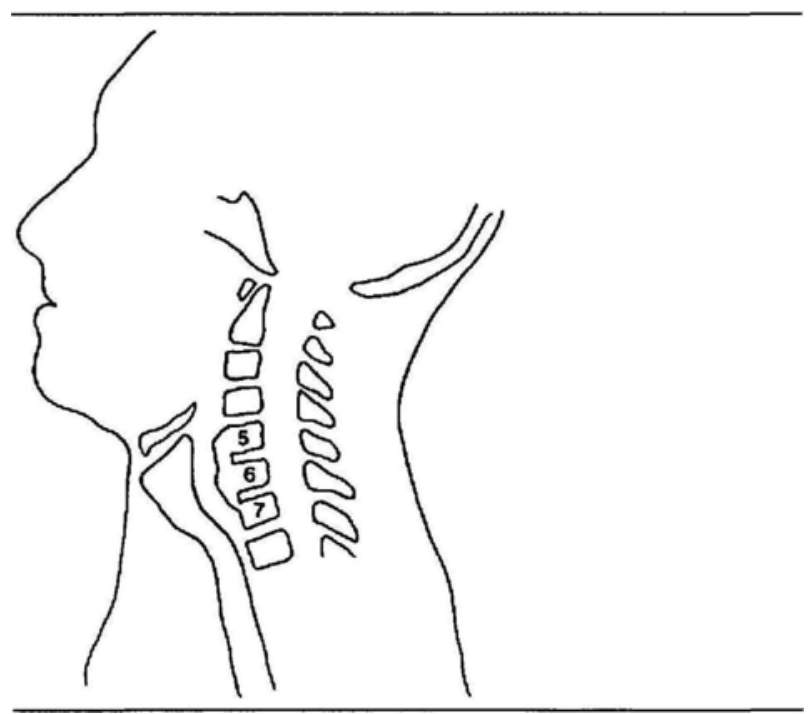

FIGURE 2 The effect of the anterior osteophytes at $\mathrm{C}_{5-7}$ on the anatomy of the airway is detailed. There is anterior displacement of the larynx at the $\mathrm{C}_{5-7}$ vertebral levels and posterior angulation at the cervicothoracic junction as well as a tracheal stenosis at this latter level.

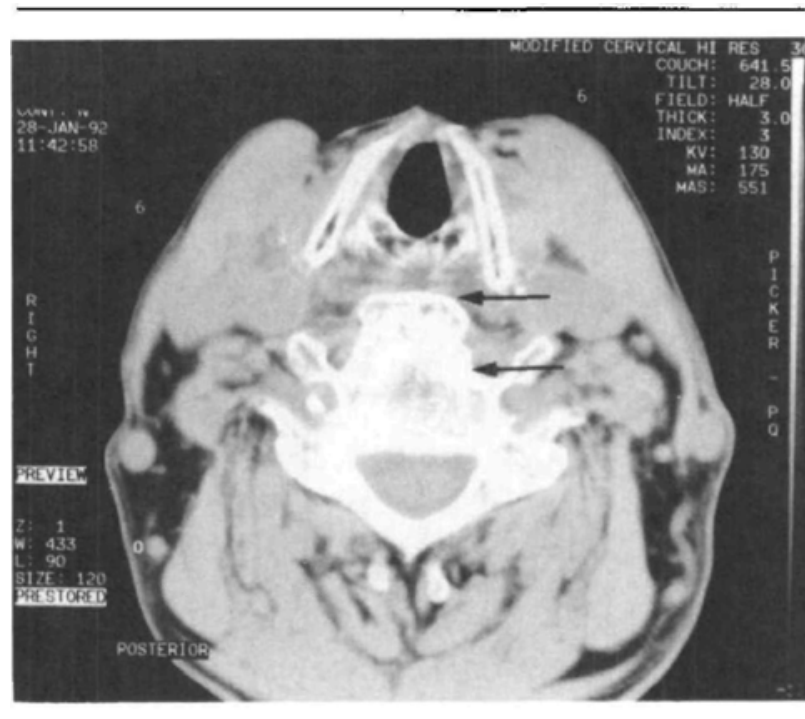

FIGURE 3 Magnetic resonance image at the $\mathrm{C}_{6}$ vertebral level demonstrating a $14 \mathrm{~mm}$ anterior osteophyte (arrows). There is anterior displacement of the larynx at this level.

\section{Discussion}

A case is reported in which prominent osteophytes at the midcervical level, in combination with subglottic tracheal stenosis, resulted in unexpected difficulties during tracheal intubation. Normally, to provide optimal conditions for direct laryngoscopy and tracheal intubation, correct positioning of the head and neck to achieve alignment of the axes of the mouth, pharynx and larynx is necessary. The upper cervical spine is extended with the degree of extension increasing from $\mathrm{C}_{4}$ to $\mathrm{C}_{1}{ }^{4}$ Both the atlanto-occipital and atlantoaxial joints are extended and extension of the atlantoaxial joint is probably near maximum. Degenerative conditions of the cervical spine may result in a decreased range of spinal motion and loss of flexion-extension may result in an inability to align the axes and allow for adequate visualization. The extreme example of this would be the fused spine of ankylosing spondylitis in which virtually no flexionextension movement is possible. Intubation difficulties encountered in patients with rheumatoid arthritis are probably accounted for both by the decrease in the range of spinal motion in severe disease as well as the rotational deformity in the shortened cervical spine of the vertically subluxed rheumatoid patient. ${ }^{5}$ Radiologically this may be appreciated as a scoliotic deformity of the larynx and trachea, best demonstrated in an anteroposterior view. Age-related osteoarthritic changes in the cervical spine also reduce the range of motion in the cervical spine. These are rarely cited as a cause of difficult intubation and this is probably because the reduction in the range of motion is not excessive and the predominant decrement 
in movement occurs at the $\mathrm{C}_{5.7}$ motion segments. ${ }^{6}$ This is not likely to have an impact on the ease of intubation. Lee has reported difficult intubation related to hypertrophic bony changes on the anterior aspects of the $\mathrm{C}_{5-7}$ vertebral bodies with both rotation and displacement of the trachea. ${ }^{7}$ The radiological description proffered by Lee is similar to that of our patient and Lee's report may represent the first case report of difficult intubation secondary to DISH. As well, calcification of the anterior longitudinal ligament at the atlanto-occipital joint may limit spinal movements and has also been cited as a rare cause of difficult intubation. ${ }^{8}$

Diffuse idiopathic skeletal hyperostosis is an ossifying diathesis leading to bone formation in spinal and extraspinal sites, paravertebral osteophyte formation and ligamentous calcification with ossification. ${ }^{9}$ The thoracolumbar spine is more frequently and severely involved than the cervical spine although isolated or predominant cervical spine involvement has been reported. Abnormalities are more common in the lower cervical spine $\left(\mathrm{C}_{47}\right)$ but the entire cervical spine may be affected. Forestier described three stages in the evolution of the disease. ${ }^{10}$ Initially there is a laminated thickening across the intervertebral disc space anteriorly. The prevertebral thickening is accentuated and eventually there is fusion and ossification of the prediscal space and ossification of the anterior longitudinal ligament. The bony flow across the space is much greater than that seen in ankylosing spondylitis. There is a common occurrence of skip areas of involvement and this, coupled with the lack of involvement of the apophyseal joints, leads to the greater preservation of local spine motion. " In patients with severe and extensive disease, $\geq 5$ contiguous spaces involved, the spine may fracture as a long bone with relatively minor trauma in a fashion analogous to ankylosing spondylitis (AS). However, the fracture tends to occur through the vertebral body and not at the disc space as it does in AS. In a review of 245 cases, Forestier noted that men were more commonly involved $(65 \%)$ than women, that the disease was rare before the age of $50 \mathrm{yr}$ and was more common with advancing age. ${ }^{10}$ As well, DISH may be more common in diabetics. Because DISH and osteoarthritis develop with predilection in comparably aged patients it is not surprising to find features of both conditions in the same patients. It may, as well, be associated with ossification of the posterior longitudinal ligament (OPLL), especially in the midcervical level. ${ }^{9}$ Ossification of the posterior longitudinal ligament may result in posterior osteophyte formation, reduction in the spinal canal lumen, cord compression and neurological dysfunction. Our patient had both clinical and radiological evidence of OPLL. Forestier reported that symptoms were not common in patients with DISH and it is possible that the signs and symptoms in some patients are related more to the associated syndromes of osteoarthritis (predominantly stiffness) and OPLL (neurological dysfunction).

Anterior bone deposition in the cervical spine in patients with DISH will have variable effects on the anatomy of the airway depending not only on the levels involved but also the amount and orientation of the bone deposited. In our patient, it is likely that the extensive bone deposition centred around the mid-cervical level resulted in anterior displacement of the larynx. The lack of involvement of the lower cervical spine resulted in posterior displacement of the upper trachea with respect to the larynx and the net effect was an acute angulation of the airway (Figure 2). Immediately below the angulation was a subglottic tracheal stenosis resulting in a considerable reduction in the lumenal diameter of the trachea. Difficulty was encountered in traversing the angulation and the stenosis with all but the smallest of endotracheal tubes. Although speculative, it is possible that had the patient's disease been more extensive, that is involving the lower cervical spinal levels as well, then the airway would not have been so angulated and that less difficulty would have been encountered during intubation.

The increasing interest over the last decade, in the preoperative recognition of the patient whose trachea will be difficult to intubate, has prompted the development and publication of a number of methods for airway evaluation. ${ }^{1,2}$ Unfortunately, prospective evaluation of these methods has revealed that only about $50 \%$ of the patients whose tracheas were difficult to intubate were identified preoperatively by application of these criteria. ${ }^{12}$ This is likely due to the fact that it is the combination of factors that will predict difficulty of direct laryngoscopy and that the total combined effect of these factors may be difficult to appreciate. Methods of evaluation that involved combining criteria from a number of protocols appear to be more sensitive in predicting difficult intubation although false positives are common. ${ }^{13}$ Isolated abnormalities of the cervical spine are rarely the cause of difficult intubation. Patients with shortened occipito-atlantal or cervical intervertebral distances from any cause and those with extensive congenital or acquired spinal fusion likely represent the largest proportion of this small group. $\mathrm{Pa}$ tients such as the one reported here, with less extensive but highly relevant anatomical distortions that render laryngoscopy or intubation difficult, are rare. It is possible that the anatomical abnormality is symptomatically silent and even a high index of suspicion would be insufficient to prompt sufficiently extensive preoperative evaluation so as to identify the lesion. Although radiological evaluation may be a useful predictor of difficult intubation in this patient population, a recommendation to screen 
routinely large segments of the patient population (i.e., all elderly patients with osteoarthritis) for exceedingly rare entities cannot be entertained. Rather, careful clinical patient evaluation to identify as many patients with difficult airways as possible before surgery and an appropriate algorithm for the management of the unanticipated difficult intubation are recommended.

\section{References}

1 Mallampati $S R$, Gatt $S P$, Gugino $L D$, et al. A clinical sign to predict difficult tracheal intubation: a prospective study. Can Anaesth Soc J 1985; 32: 429-34.

2 Wilson ME, Spiegelhalter D, Robertson JA, Lesser P. Predicting difficult intubation. Br J Anaesth 1988; 61: 211-6.

3 Gronert GA, Theye RA. Pathophysiology of hyperkalemia induced by succinylchöline. Anesthesiology 1975; 43: 89-99.

4 Horton WA, Fahy L, Charters P. Disposition of cervical vertebral, atlanto-axial joint, hyoid and mandible during $x$ ray laryngoscopy. Br J Anaesth 1989; 63: 435-8.

5 Keenan MA, Stiles CM, Kaufman RL. Acquired laryngeal deviation associated with cervical spine disease in erosive polyarticular arthritis. Use of the fibreoptic bronchoscope in rheumatoid arthritis. Anesthesiology 1983; 58: 441-9.

6 Hayashi H, Okada K, Hamada M, Tada K, Ueno R. Etiologic factors of myelopathy. A radiographic evaluation of the aging changes in the cervical spine. Clin Orthop 1987; 214: 200-9.

7 Lee $H C$, Andree RA. Cervical spondylosis and difficult intubation. Anesth Analg 1979; 58: 434-5.

8 Brechner $V L$. Unusual problems in the management of airways. 1. flexion-extension mobility of the cervical vertebrae. Anesth Analg 1968; 47: 362-73.

9 Resnick D. Hyperostosis and ossification in the cervical spine. Arthritis Rheum 1984; 27: 564-9.

10 Forestier J, Lagier $R$. Ankylosing hyperostosis of the spine. Clin Orthop 1971; 74: 65-83.

11 Houk RW, Hendrix RW, Lee C, Lal S, Schmid FR. Cervical fracture and paraplegia complicating diffuse idiopathic skeletal hyperostosis. Arthritis Rheum 1984; 27 : 472-5.

12 Oates JDL, MacLeod AD, Oates PD, Pearsall FJ, Howie $J C$, Murray GD. Comparison of two methods for predicting difficult intubation. Br J Anaesth 1991; 66: 305-9.

13 Frerk $C M$. Predicting difficult intubation. Anaesthesia 1991; 46: 1005-8. 